\title{
Perspectivas do destino turístico: repensando o sentido do conceito
}

\section{Perspective of tourist destination: rethinking the meaning of the concept}

\section{Perspectiva del destino turístico: repensar el significado del concepto}

\author{
Luiz Carlos da Silva Flores ${ }^{1}$ \\ Júlio da Costa Mendes ${ }^{2}$
}

\begin{abstract}
Resumo: O turismo é uma indústria em franco desenvolvimento e o destino turístico está no centro como principal atração. Várias correntes de estudiosos e investigadores de diversas ciências como a geografia, economia, filosofia, antropologia, psicologia e administração já deram a sua contribuição para a formação do conceito do destino turístico. Este artigo tem como objetivo propor algumas reflexões sobre o uso do conceito de destino na literatura do turismo, analisar e discutir o tema. Adotou-se procedimentos de pesquisa bibliográfica e exploratória, utilizando livros, teses e artigos de periódicos científicos de grande contribuição para o área do turismo. Elaborou-se cinco abordagens sobre destino turístico, uma discussão sobre as mesmas e, então, é apresentado um quadro com as características do destino, considerando-se os limites, conteúdo, cooperação e o cliente, numa descrição que é denominada de integrada e sistêmica. Concluímos que estas abordagens não são exclusivas e sim complementares, e apresentamos uma nova forma de olhar o conceito de destino turístico, considerando o turista como principal criador da experiência que ele pretende vivenciar.
\end{abstract}

Palavras-chave: Turismo; Destino turístico; Perspectivas do turismo; Abordagem integrada.

Abstract: The Tourism is a rapidly developing industry and the tourist destination is the center as the main attraction. Various streams of scholars and researchers from various disciplines such as geography, economics, philosophy, anthropology, psychology and management have made their contribution to the formation of the concept of tourist destination. This paper aims to propose some reflections on the use of the concept of tourism destination in the literature, analyze and discuss the topic. It was adopted procedures for bibliographic and exploratory research, using books, theses and articles of scientific journals of great contribution to the area of tourism. Was elaborated five approaches to tourist destination, a discussion about them and then a picture with the characteristics of the destination, considering the limits, content, cooperation and the client, a description that is denominated an integrated and systemic is presented. We conclude that these approaches are not exclusive but complementary, and we propose a new way of looking at the concept of tourist destination, considering the tourist the main creator of the experience that he intends to live.

1 Doutor em Engenharia de Produção, Professor da disciplina de Marketing Turístico, do Programa de Pós-graduação em Turismo e Hotelaria, em nível de Mestrado e Doutorado, da Universidade do Vale do Itajaí-Univali, Balneário Camboriú - Santa Catarina/Brasil. Investigador do Grupo de Pesquisa em Hotelaria, Gestão e Serviços Turísticos. Email: luiz.flores@univali.r

2 Doutor em Gestão, ramo de Estratégia e Comportamento Organizacional. Professor Auxiliar da Faculdade de Economia/Universidade do Algarve e Membro da Coordenação do Programa de Doutoramento em Turismo. Director do Mestrado em Gestão das Organizações Turísticas. Membro do Centro de Investigação sobre Espaço e Organizações. Investigador na área da Gestão e do Turismo. E-mail: jmendes@ualg.pt 
Keywords: Tourism; Tourist destination; Tourism perspective; Integrated approach.

Resumen: El turismo es una industria en rápido desarrollo y destino turístico se encuentra en el centro como la atracción principal. Varias corrientes de estudiosos e investigadores de diversas disciplinas como la geografía, la economía, la filosofía, la antropología, la psicología y la gestión han hecho su contribución a la formación del concepto de destino turístico. Este artículo tiene como objetivo proponer algunas reflexiones sobre el uso del concepto de destino turístico en la literatura, analizar y discutir el tema. Los procedimientos adoptados para la investigación bibliográfica y exploratoria, utilizando libros, tesis y artículos de revistas científicas de gran aporte para el área de turismo. Desarrollamos cinco enfoques de destino, una discusión acerca de ellos y luego un cuadro con las características del objetivo, teniendo en cuenta el límite, el contenido, la cooperación y el cliente, una descripción que se llama un sistémico e integrado que se presenta. Llegamos a la conclusión de que estos enfoques no son excluyentes sino complementarios, y presenta una nueva forma de ver el concepto de destino turístico, mientras que los turistas como el principal creador de la experiencia que tiene la intención de vivir.

Palabras clave: Turismo; Destino turístico; Punto de vista turístico; El enfoque integrado.

\section{INTRODUÇÃO}

A UNWTO - World Tourism Organization Network classifica o destino turístico como um dos conceitos mais utilizados no Turismo, porém sobre diferentes formas e pontos de vistas, gerando discussões diversas no meio acadêmico. Framke (2002) afirma que o termo 'Destino' é utilizado por diversos atores da indústria do turismo de forma muito diferente, enfatizando apenas aquilo que lhes convém, e em alguns casos parece haver certas contradições sistemáticas no seu uso: o destino como uma narrativa, como uma atração, como uma unidade geográfica, como uma relação empírica, como um objeto de marketing, como um lugar onde o turismo acontece, e assim por diante.

Este artigo se propõe a estudar se um destino é uma unidade geográfica, uma localidade, um sistema de produção, uma unidade de produção de serviços, um objeto de marketing, um produto a ser comercializado, ou ainda, uma criação na mente do cliente. A percepção do que vem a ser uma destinação é cada vez mais uma questão subjetiva, pois depende de cada consumidor e de seu respectivo roteiro de viagens (Vianna, Anjos \& Anjos, 2012).

Existem vários olhares para o destino turístico, da geografia, da economia, da psicologia, da sociologia e da gestão. Estes se integram e se adaptam às dinâmicas do ambiente, no qual o principal demandante é o turista, que apoiado com recursos de tecnologias de informação (TI) e mobile, com acesso direto às informações e relacionamento nas redes sociais, modificou seu comportamento. Ele não quer mais ser o consumidor do produto - o turista passivo, mas sim, deseja participar do processo, interagir com as outras partes, com a comunidade. $O$ turista com os recursos que tem a sua disposição cria a sua experiência de turismo e, consequentemente, cria o seu próprio destino turístico.

Enquanto uns se preocupam com o espaço, outros com as transações comerciais e gestão e outros ainda com as relações sociais e experiências dos turistas. Sabe-se que o destino existe e é complexo, devido a todas as relações que acontecem entre os produtores, consumidores, partes 
interessadas e comunidade. Nisso prende-se a importância do destino ser compreendido quanto ao limite, conteúdo, cooperação e clientes (Framke, 2002), e dessa forma se estabelecer instrumentos para o gerenciamento dos recursos e comercialização.

Considerando os diversos estudos desenvolvidos até o momento sobre o uso do termo 'destino turístico', e o trabalho desenvolvido por Framke (2002), apresentou-se o seguinte questionamento de pesquisa: como um destino turístico pode ser definido quanto às características de limite, conteúdo, relações e turistas, numa visão sistêmica e integrada?

Assim, definiu-se como objetivo propor algumas reflexões sobre o uso do conceito de destino na literatura do turismo, analisar e discutir o tema. Para isso, investigou-se as diferenças relacionadas ao termo destino nas perspectivas geográfica, econômica, sociológica e gestão. 0 artigo não discute o sistema de turístico (Leiper, 1979; Anjos, 2004; Beni, 2007), mas trata da compreensão do destino a partir das discussões de limitação geográfica, conteúdo, cooperação e turistas propostas por Framke (2002). Bem como, outros aspectos do destino não foram abordados, por exemplo, o papel da população local, as questões ambientais, o processo de planejamento ou as economias locais.

Para alcance do objetivo, a discussão do termo destino turístico, foram adotados procedimentos de pesquisa exploratória e bibliográfica. A pesquisa bibliográfica foi realizada em livros, teses e artigos, de periódicos e anais de eventos científicos da área do turismo disponíveis até dezembro de 2013, nas bases de dados B-On, Ebsco Host e Sciencedirect. Foram utilizados periódicos de grande contribuição do turismo, nacionais e internacionais, como International Journal of Hospitality Management, Journal of Travel Research, Tourism Management, Tourism Management Perspectives, Scandinavian Journal of Hospitality and Tourism entre outros, e nacionais como Seminário Anual da Associação Nacional de Pesquisa e Pós-graduação em Turismo - ANPTUR, Revista Brasileira de Turismo (RBTUR) entre outras. Os artigos foram escolhidos de acordo com a contribuição ao objeto de estudo para montar as perspectivas e possibilitar a discussão do termo destino turístico.

Este artigo mostra o resultado da pesquisa de pós-doutoramento, com recursos da CAPES/FCT, que aprofundou o conhecimento sobre o constructo destino turístico, e está composto de quatro partes. Na primeira parte apresenta-se a contextualização do tema, os objetivos do trabalho e os procedimentos metodológicos; na segunda descreve-se as perspectivas geográfica, econômica, sociocultural, da psicologia e da gestão. Em seguida, discute-se sobre os conceitos, a abordagem holística e a abordagem integrada e sistêmica, onde se propõe um quadro com as características de um destino turístico. E concluí-se com a discussão sob a ótica da abordagem integrada e sistêmica do destino turístico.

\section{PERSPECTIVAS SOBRE O DESTINO TURÍSTICO}

Nesta parte apresentam-se cinco perspectivas sobre o destino turístico que influenciaram o direcionamento dos estudos sobre o tema, podendo-se observar que elas não são sequenciais e 
nem excludentes, mais sim evolutivas com as mudanças ambientais.

\subsection{Perspectivas da geografia}

A geografia está entre as ciências que mais tem influenciado as pesquisas sobre o turismo e consequentemente o destino turístico devido as suas áreas de atuação, física, econômica e política. A geografia do turismo tem como objetivo o estudo do espaço, das relações e fenômenos decorrentes das viagens e estadias temporárias de pessoas, principalmente, com fins recreativos e de lazer (Mitchell, 1994). Este autor descreve ainda que a geografia do turismo se preocupa com os padrões de utilização de lazer e viagem, tal como ocorre no espaço. A visão panorâmica do geógrafo do turismo examina o destino, primeiro, relacionando a oferta e as ligações no espaço, e segundo, relacionando os conceitos de propósito, estrutura e distribuição, assumindo que há um objeto fundamental por trás das decisões e ações de turistas e outras partes interessadas da indústria do turismo.

Para a geografia, o destino turístico apresenta-se numa área com limites físicos definidos, configurando-se um elemento integrante do sistema turístico e descrito por Leiper (1979) como o lugar que possui recursos naturais ou construídos pelo homem, contribuindo de forma inerente para as atrações e atraindo turistas para ficarem temporariamente. Cooper (2001) ratifica que são as atrações de uma localização geográfica que fazem os turistas desejar visitá-la, e complementa que as demandas modificam a estrutura e o caráter do destino pela geração de ofertas e mudanças nos seus elementos constitutivos, sendo que essas mudanças devem ser objeto de planejamento e desenvolvimento do turismo.

O sistema turístico é colocado em movimento por meio do turista pelo deslocamento que realiza entre a sua região de origem - região emissora - e o destino - região receptora. Para o funcionamento do sistema, primeiramente há a decisão do turista em viajar, influenciado por diversos fatores, tais como as motivações pessoais, a imagem que ele tem do lugar e as vantagens comparativas existentes entre os diferentes destinos alternativos. A partir da decisão do turista é requerido um conjunto de serviços (seja de transporte, alojamento, alimentação, entre outras atividades públicas ou privadas), que são oferecidos em espaços geográficos bem definidos, necessários para efetivação da viagem (Anjos, Anjos \& Oliveira, 2013; Acerenza, 1987).

Segundo Becker (2014, p.56) a principal relação entre a geografia e o turismo vai se estabelecer no espaço geográfico como alicerce da oferta turística. "[...] Assim, o espaço geográfico modifica-se constantemente, e as paisagens incorporam novos objetos e novas técnicas criadas pelo conhecimento e pelo trabalho humano, elaborando bens e serviços necessários à satisfação da necessidade turística e que se exprimem no consumo turístico".

Ou seja, a destinação turística é o foco de instalações e serviços que são projetados para atender às necessidades dos turistas. Observa-se que para a geografia o objeto está na análise do movimento turístico e seu impacto, bem como que uma destinação une todos os aspectos do turismo, a demanda, o transporte, a oferta e a comercialização, em uma estrutura conveniente 
para visitação.

\subsection{Perspectivas da economia}

A movimentação da indústria do turismo chamou a atenção dos cientistas econômicos que passaram a investigar o comportamento do lado da procura, buscando uma compreensão do sistema de oferta, da organização e dos aspectos de definição das políticas públicas e respectivo enquadramento econômico.

Não existe nenhuma razão para supor que o mercado, por si só, proporcione o uso mais eficiente dos recursos e responda da melhor forma às preferências dos consumidores. Existem muitas imperfeições no mercado e, dessa forma, há a necessidade de intervir - através do desenvolvimento de estratégias, métodos e técnicas de planejamento, de organização e de controle tendentes a influenciar a oferta e a demanda turísticas da região - tentando, de uma maneira sistemática, alcançar objetivos comuns e resultados que não ocorreriam se não houvesse regulação (Mendes, 2004; Davidson \& Maitland, 1997).

O processo de planejamento e gestão de territórios turísticos de acordo com Anjos, Anjos \& Oliveira (2013) deve ter como pressuposto a visão sistêmica, possibilitando a compreensão da complexidade do mundo real, cada vez mais perceptível como recurso indispensável para enfrentar os desafios de ordem econômica, financeira e mercadológica. E complementam que a produção de um destino turístico depende de programação integrada e interdisciplinar, assim como o equilíbrio do conjunto, se constituindo fator determinante que se realiza acompanhando passos, critérios e fatos, atraindo também investidores que impulsionam a expansão da cidade caracterizando o turismo como fonte econômica do destino.

Neste sentido, Cracolicia e Nijkamp (2008) argumentam que uma destinação turística deixa de ser um conjunto distinto de recursos naturais, culturais ou ambientais, assumindo uma configuração de um produto global, atraente e disponível em uma determinada área, uma carteira complexa e integrada de serviços turísticos produzidos com base em seu potencial autóctone, oferecido por um destino com objetivo de proporcionar uma experiência de férias e satisfazer as necessidades dos turistas.

Segundo Andergassen, Candela e Figini (2013) a economia de destinos estuda a relação entre a demanda (diferentes tipos de turistas hospedados no destino) e suprimento (pelo mix de firmas localizadas no território) para todo o produto turístico. Em geral, um destino pode oferecer diferentes tipos de férias para os diferentes tipos de turismo, cada um possivelmente caracterizado por um mix diferente de produtos e serviços específicos, incluindo os recursos locais e alojamento. Portanto, o produto de turismo é constituído por todos os bens e serviços específicos do destino e não específicos do turismo que são exigidos durante um dia de férias, a sua quantidade é medida através do número de dormidas e seu valor é o preço da diária. Nesta visão o turista é um consumidor dos recursos turísticos. 


\subsection{Perspectivas socioculturais}

Utilizou-se para o objetivo deste artigo o enquadramento da sociologia e antropologia dentro das perspectivas socioculturais, denominação utilizada por Saraniemi e Kylanen (2010) e Framke (2002), e cujos olhares estão para os contextos sociais e culturais, as relações envolvendo os consumidores e produtores do produto global, o destino turístico, sua estrutura social, política, organizacional e processos.

Segundo Framke (2002) na compreensão sociológica o destino turístico é apresentado como o resultado da prática social, sendo que cada atividade acontece em um lugar, e essas atividades formam o lugar. Mudanças de atividades alteraram o caráter espacial de um lugar, ou seja, a sua estrutura, o conteúdo, o significado e o tamanho. Isto significa que um destino não é uma aglomeração física de instalações e empresas, mas um processo que, a qualquer momento, se remodela, através dos olhos dos atores que participam desse processo.

Já a Antropologia discutida por Graburn e Moore (1994), estuda as diferenças e semelhanças da cultura das pessoas e povos no tempo, buscando compreender o processo de mudança ambiental, inovação e conflitos intraculturais. Nesta o interesse pelo turismo é provocado pela movimentação dos turistas que impactam na variação intracultural, ou seja, a diferenciação dentro de culturas como etnia, gênero, classe e idade; bem como os impactos sobre a cultura expressiva, particularmente as artes étnicas que se tornam mercadorias para o comércio turístico. Outra área de investigação está relacionada ao caráter de interação intercultural e da comunicação entre os turistas e os residentes. Como fatores impulsionadores do estudo do turismo por antropólogos, psicólogos, sociólogos e outros profissionais que estudaram as motivações turísticas e o destino turístico na vida das pessoas.

\subsection{Perspectivas da Psicologia}

Os estudos da psicologia envolvem duas perspectivas, micro e macro. A primeira, como descreve Ross (1998), está relacionada à psicologia do indivíduo e sua aplicação para a compreensão do comportamento e motivação dos turistas, da personalidade e atitudes do turista e a percepção turística do meio ambiente. Por outro lado, a macro, abrange o estudo da sociedade e das organizações do turismo, envolvendo contextos sociais, comunitários e de conceitualizações do trabalho, bem como a gestão destes contextos sociais, como marketing, recursos humanos, recursos turísticos, avaliação de instalações e os impactos sociais do turismo sobre as comunidades anfitriãs.

Segundo Tang (2014), a psicologia social tem sido definida como uma ciência que analisa e procura compreender a influência do imaginário no pensamento, experiência e comportamento do indivíduo. Complementa o autor que o comportamento psicológico social leva em consideração não só o que está ocorrendo para o indivíduo, mas também o comportamento social e a interação social. $\mathrm{Na}$ indústria do turismo tem sido muito utilizado para estudar a experiência de consumo e a 
influência de outras pessoas, como trabalhadores, funcionários, gestores, residentes e outros consumidores.

Devido à sua natureza pragmática, a gestão do turismo utiliza-se de recursos da psicologia e de outras disciplinas para fornecer subsídios aos gerentes e outros profissionais da indústria para problemas diversos de gestão, tais como marketing, pesquisa e desenvolvimento, recursos humanos e administração estratégica (Tang, 2014).

Atualmente têm sido ampliados os estudos sobre a experiência no turismo, que segundo Kastenholz, Carneiro, Marques \& Lima (2012) são de alta complexidade, envolvendo dimensões como o emocional, o social, particularmente em relação às interações específicas entre turistas e anfitriões, e o cognitivo, associado com as percepções das características do destino, tais como paisagem, infraestrutura, atrações e sensescapes. Assim, o estudo da experiência turística não está restrito aos valores funcionais ou de serviços públicos, mas incluem dimensões sociais, emocionais, hedônicas e simbólicas, mediadas pelos sentidos.

Segundo Kastenholz et al. (2012) a experiência do turismo é co-criada e vivida por vários agentes do destino: os turistas, os provedores de serviços da população e turismo locais. Os turistas assumem um papel ativo na definição de sua experiência, iniciando o processo buscando informações sobre a viagem, imaginando atividades e ativando a rede de serviços disponíveis no destino. Além disso, a natureza da participação dos turistas durante a experiência será fundamental para a maneira como eles se lembrarão dela.

Com isso, segundo os autores, modifica-se o conceito de destino e um dos maiores desafios para os gestores está em fornecer experiências de alta qualidade e a satisfação dos diversos segmentos turísticos. Para isso são necessários à compreensão das motivações individuais, expectativas, percepções e significados associados a esta experiência subjetiva é, portanto, essencial para fornecer experiências de alta qualidade.

\subsection{Perspectivas da gestão}

A preocupação em responder a um amplo conjunto de necessidades e exigências dos turistas durante uma estada, a variedade de atores e de organizações envolvidas no processo, tanto do setor privado, quanto do setor público, os diferentes objetivos e regras que governam as suas ações e a intensidade de interações que se estabelecem entre todas as partes têm levado a que, cada vez com mais insistência, um significativo corpo da literatura realce a necessidade de se encararem os destinos turísticos como entidades que, à semelhança das demais, devem ser objeto de gestão (Mendes, 2004; Silva, Mendes \& Guerreiro, 2001; Manente \& Furlan, 1998; Davidson \& Maitland, 1997; Laws, 1995; Middleton, 1994; Ritchie \& Crouch, 1993).

A fase de gestão do turismo é caracterizada por duas abordagens. A primeira identificando a necessidade de comercializar o produto-destino, de modo a atrair visitantes suficientes para sustentarem as atividades de negócios do turismo; e a segunda pela adoção de métodos administrativos para assegurar formas benéficas de turismo. Durante esta fase de gestão, as 
autoridades turísticas começam a tomar decisões proativas sobre as facilidades que irão oferecer, tentando antecipar as procuras e mudanças de gostos dos visitantes e tentando influenciar as suas experiências (Mendes, 2004; Laws, 1995), principalmente o planejamento de destino.

O processo de gestão em um destino turístico deve estar sustentado num planejamento que resulta de um comprometimento dos responsáveis das coletividades locais e que traduza uma adesão do conjunto dos atores turísticos. Muitas das decisões relativas à gestão dos destinos turísticos e ao planejamento da oferta global, da imagem e do controle das atividades dos operadores são orientadas para a renovação de locais, de cidades, para a revitalização de destinos maduros ou em fase de declínio, os quais, indubitavelmente, necessitam de intervenção programada. Assim, os objetivos da gestão estão mais centrados na projeção e no estabelecimento de um novo destino (Mendes, 2004; Davidson \& Maitland, 1997) e, por conseguinte, no atendimento das necessidades, satisfação e excelência da experiência do turista.

Com isso, o destino turístico deverá ser suportado por uma estrutura de gestão que lidere e assegure a direção do desenvolvimento turístico na região, que gere os recursos, que coordene o trabalho em conjunto das diferentes partes do sistema, que estabeleça objetivos e prossiga estratégias, que permita ao destino competir mais eficazmente do que em outras circunstâncias (Mendes, 2004).

Finalizando esta parte, demonstra-se no Quadro 1 uma síntese dos resultados das investigações de Framke (2002) sobre os contributos das áreas - de um lado a convencional e negócio, que inclui a geografia e economia, e de outro lado a sociocultural que contempla a sociologia e a antropologia -, considerando as dimensões de limite, conteúdo, cooperação e turista, para a caracterização do destino turístico.

Quadro 1 - Caracterização de um destino turístico

\begin{tabular}{|l|l|l|}
\hline Dimensões & Convencional / negócio & Sociocultural \\
\hline $\begin{array}{l}\text { Limitação } \\
\text { geográfica do } \\
\text { destino }\end{array}$ & $\begin{array}{l}\text { - O destino é um lugar importante. } \\
\text { - Não há consenso sobre características } \\
\text { espaciais: “destinos" são unidades sem } \\
\text { limites geográficos, existem em vários } \\
\text { níveis geográficos e/ou administrativos. }\end{array}$ & $\begin{array}{l}\text { - Destino é um lugar sem limites geográficos } \\
\text { definidos, desenvolvido por meio de } \\
\text { processos contínuos de interação social. } \\
\text { - Destinos são estruturas, imagens, resultado } \\
\text { da prática social. }\end{array}$ \\
\hline $\begin{array}{l}\text { Conteúdo do } \\
\text { destino }\end{array}$ & $\begin{array}{l}\text { - Estático na aglomeração no núcleo de } \\
\text { atrações e serviços periféricos. } \\
\text { - Dinâmico em relação à procura turística. }\end{array}$ & $\begin{array}{l}\text { - O processo dinâmico molda o lugar onde o } \\
\text { turismo acontece. } \\
\text { - Não há descrição clara do conteúdo. } \\
\text { - Atrações, cultura, eventos, paisagens e } \\
\text { serviços. }\end{array}$ \\
\hline destino & $\begin{array}{l}\text { - Entendimento implícito da necessidade } \\
\text { da cooperação. } \\
\text { - Não há discussão de caráter e significado } \\
\text { para a cooperação em um destino. }\end{array}$ & $\begin{array}{l}\text { - Não há descrição de cooperação no destino. } \\
\text { outra especificação. }\end{array}$ \\
\hline \multirow{2}{*}{ O turista } & $\begin{array}{l}\text { - É visto como um consumidor econômico } \\
\text { do destino. } \\
- \text { A evolução da demanda muda a } \\
\text { estrutura e o conteúdo do destino }\end{array}$ & $\begin{array}{l}\text { - É um ator social e consumidor buscando } \\
\text { uma experiência. } \\
\text { - A demanda turística cria práticas sociais } \\
\text { formando o turismo espacial. }\end{array}$ \\
\hline
\end{tabular}

Fonte: Framke, 2002, p.102 (nossa tradução). 
Como conclusão de suas pesquisas apresentada no Quadro 1, Framke (2002, p.105) descreve que a identidade de um destino é formada pela soma de interesses, atividades, instalações, infra-estrutura e atrações. "O destino tem uma dimensão estática - o lugar - e uma dimensão dinâmica - a mistura e aglomeração de agentes e produtos/serviços, variando historicamente com a mudança da demanda dos turistas".

A partir destas visões diferentes sobre o destino e condensadas no Quadro 1 acima, podese abrir varias discussões sobre o que é um destino turistico, destacando diversas definições da literatura do turismo que complementam e atualizam o destino turístico.

\section{DISCUSSÃO}

Pode-se verificar na leitura das perspectivas apresentadas anteriormente e demonstradas no Quadro 1 que não existe consenso no corpo da literatura sobre o conceito de destino turístico. Cada autor, na linha da disciplina ou da área do saber em que se insere, interpreta e define destino turístico de acordo com a perspectiva e a visão que lhe são próprias. O conceito é ambíguo e subjetivo, precisamente porque é utilizado e percebido segundo óticas distintas, com significados diferentes para os vários atores envolvidos. Segundo Framke (2002) o conceito de destino turístico parece conter contradições sistemáticas no seu uso que podem gerar mais confusão em vez de clareza: o destino turístico tem sido descrito tanto como uma narrativa, uma atração, uma unidade geográfica, uma relação empírica, um objeto de marketing ou ainda como um lugar onde o turismo acontece. Alguns conceitos de destinos turísticos utilizados na vasta literatura do turismo são apresentados com o objetivo de ilustração e discussão.

Uma conceituação bem aceita pelos atores do turismo é a descrita por Travis e Gunn (apud Silva \& Silva, 1992, p.3), de que o destino turístico é "um instrumento baseado numa lógica coerente e integradora que inclui recursos naturais, população, transportes, atrações, imagem e equipamentos e infraestruturas turísticas". Para Bieger (apud Manente \& Cerato, 2000, p.16) destino turístico é uma "área que congrega todos os produtos e ofertas que os turistas consomem durante a sua estadia". Numa descrição no paradigma econômico, o destino é uma "estrutura de oferta de produtos e serviços turísticos, coerente e circunscrita a uma área geográfica, detentora de uma imagem aglutinadora, comercializada de forma integrada e sob uma marca distintiva" (Silva et al., 2001, p.72). Numa visão do sistema turístico, Mill e Morrison (apud Framke, 2002, p.94) descrevem o destino como "uma parte do sistema turístico, composto por um mistura de elementos interdependentes".

Verifica-se que a visão mais comum do destino turístico é a de território ou área geográfica, possuindo diferentes características naturais ou construídas pelo homem, que atraem turistas para uma visita. Porém Framke (2002) questiona essa compreensão do destino e cita Leiper (2000), que argumenta "não haver nenhuma evidência de que qualquer destino já atraiu, em sentido literal, os turistas". E complementa que os principais fatores causais de fluxos turísticos estão nas regiões geradoras do viajante, nos lugares onde as viagens começam, onde as 
forças que estimulam as motivações dos turistas estão localizadas.

Com frequência as destinações são delimitadas por barreiras políticas e geográficas criadas de maneira artificial, que não levam em consideração os desejos e necessidades dos consumidores e nem as funções que afetam ao setor do turismo. Desta forma, uma destinação pode ser considerada como uma combinação de todos os produtos oferecidos sob uma denominação qualquer, em um determinado local específico e que serão consumidos localmente, não podendo ser armazenados e nem transportados para outro local (BUHALIS, 2000).

Neste sentido Vianna, Anjos e Anjos (2012) esclarecem que uma destinação turística é um local geográfico, em direção ao qual deve dirigir-se a demanda, para desfrutar de uma viagem, bem como o caminho percorrido entre a origem e o destino faz parte da experiência turística, e o lugar para onde se encaminha o turista é o núcleo turístico (no caso de um parque temático, por exemplo), uma zona turística (como a Serra Catarinense), um município turístico (como Balneário Camboriú) ou uma região (como a Grande Florianópolis), sendo todos eles considerados como destinos turísticos, ou seja, o local que serve como objetivo da viagem.

Neste contexto, considera-se que o conceito de destino turístico pode e deve ser objeto de abordagens mais holísticas e integradas, que permitam uma leitura e uma visão dinâmica sobre a realidade que caracteriza este fenômeno.

A UNWTO vem adotando uma abordagem holística, incluindo aspectos das perspectivas geográficas, econômicas, socioculturais, psicológicas e de gestão, atribuindo maior amplitude ao termo destino turístico, e assim o descreve:

Um destino turístico é um espaço físico no qual um visitante pernoita pelo menos uma noite. Inclui produtos turísticos tais como, serviços de suporte, atrações e recursos turísticos a um dia de viagem de regresso. Tem fronteiras físicas e administrativas que definem a sua gestão, e tem também imagens e percepções que definem a sua competitividade no mercado. Os destinos turísticos incorporam vários stakeholders que geralmente incluem a comunidade local, e podem ainda, abrigar e formar, uma rede maior de destinos (UNWTO, 2010).

Pode-se observar nesta definição que o destino turístico caracterizado como um espaço físico que inclui atrações, produtos, serviços e recursos turísticos, possuindo fronteiras físicas e administrativas que definem a gestão.

Algumas das características mais destacadas pelos autores são aquelas que compõem o produto destino turístico, porém, este produto faz parte de um sistema maior que inclui entradas, saídas, processos e pessoas. Este último elemento, pessoas, aparece nas diversas etapas e componentes do destino, com grande influência na concepção, nos processos e na entrega do produto. Está nas características do turismo que o produto é consumido onde é produzido e o cliente interage diretamente com as pessoas da produção, aumentando assim a complexidade de gerenciamento.

Considerando o turismo uma atividade inerente de sociedade humana, envolvendo relações sociais entre turistas e a comunidade, com as organizações fornecedoras dos produtos e 
serviços, bem como a relação entre estas organizações, pode-se identificar a grande complexidade que é o destino. $O$ ambiente onde se produz o turismo é formado por atrações naturais ou construído pelo homem, virtuais, diversas entidades, pessoas com diversos interesses, e recursos materiais e financeiros. Então, estas partes constituídas formam um sistema - o sistema destino turístico, que está situado num ambiente formado pelos turistas, comunidade, atrações, recursos, serviços e diversos stakeholders. Como características dos sistemas abertos essas partes interagem entre si, e influenciam umas às outras, e como forma de reação ao ambiente, acontecem às adaptações ao ambiente.

No sistema turístico discutido por Anjos, Anjos \& Oliveira (2013, p.399) os grupos sócioterritoriais, que incluem os turistas e os residentes, tem uma diversidade de interesses que muitas vezes são convergentes e outras vezes antagônicos. "Devido às multiplicidades de formações sociais e a relação que mantém com o destino (visitante esporádico, segundo residente, cliente fiel do destino, cliente de uma rede de hotéis) remetem à necessidade de compreensão da diversidade dos turistas de forma singular". Dessa forma, estes grupos possuem uma influência muito grande nas mudanças e adaptações do destino ao ambiente.

Argumenta-se assim que o destino, numa abordagem integrada e sistêmica, é um constructo essencialmente concebido, arquitetado, definido pelo cliente. Admite-se que seja desenvolvido em torno de narrativas, de informação promocional, de word of mouth e enriquecido depois com expectativas e com vivências programadas pelos próprios turistas. Neste sentido, são os turistas que criam e consubstanciam este constructo sem limites nem fronteiras, utilizando - ou não - estruturas que numa lógica de mercado são criadas para ir precisamente ao encontro das suas necessidades e expectativas. Assim, defende-se que o destino turístico deverá ser entendido e interpretado essencialmente como um sistema criado e desenvolvido na mente do turista.

A utilização de espaços, o consumo dos serviços, as experiências num hotel, numa cidade, na natureza, em diferentes locais programados, fazem parte integrante de uma nova abordagem ao conceito a partir das perspectivas de quem vai viver a realidade - os turistas. O sistema é concebido, experimentado e memorizado pelos turistas. Neste sentido, e a partir das dimensões de Framke (2002), descreve-se no Quadro 2 uma nova visão de destino turístico: 
Quadro 2 - Uma nova abordagem do conceito de destino turístico

\begin{tabular}{|c|c|}
\hline Dimensões & Visão Integrada \\
\hline Limitação geográfica do destino & $\begin{array}{l}\text { - o destino é um sistema onde a experiência turística } \\
\text { acontece } \\
\text { - os limites e fronteiras são virtuais ou não existem } \\
\text { - destino é a experiência criada pelo turista }\end{array}$ \\
\hline Conteúdo do destino & $\begin{array}{l}\text { - o turista descreve o conteúdo do destino } \\
\text { - processo é dinâmico e interativo } \\
\text { - composto pelo local, atrações, cultura, eventos, paisagens } \\
\text { e serviços } \\
\text { - adaptação às mudanças do ambiente }\end{array}$ \\
\hline Cooperação no destino & $\begin{array}{l}\text { - redes de cooperação público-privada, devem ser formadas } \\
\text { - interação entre as partes para a experiência de sucesso } \\
\text { - organizações de gestão que tem função de integrar } \\
\text { esforços e gerir recursos }\end{array}$ \\
\hline O turista & $\begin{array}{l}\text { - É parte integrante da cadeia produtiva } \\
\text { - Co-criador do sistema e do produto turístico }\end{array}$ \\
\hline
\end{tabular}

Nesta visão integrada o destino turístico é diferente do lugar, assim, não tem limites geográficos, políticos e/ou administrativos; é um sistema onde acontece a experiência turística e seus limites são virtuais e estão na mente e no imaginário do turista. Como explica Crouch (2007 apud Vianna, Anjos \& Anjos, 2012) uma experiência a ser vivida pelo turista em um determinado local, não possui as mesmas características de um produto turístico convencional, pois não depende apenas da estrutura que o produz, mas, sim, do resultado da ação integrada de todas as empresas envolvidas na exploração da atividade turística naquela localidade (tais como: hotéis, restaurantes, empresas de transporte, operadoras de turismo, etc.), além de empresas de suporte e outras instituições de apoio (como: grupos artísticos, equipes de entretenimento, grupos esportivos, elementos recreativos, etc.), órgãos de gestão da destinação (tanto privados como públicos), o setor público (em todos os níveis: federal, estadual e municipal), os residentes locais e todos os demais públicos envolvidos.

Assim, todos os cenários e motivações são essenciais para a construção mental que o turista desenvolve sobre um destino turístico. A lógica do sistema e a experimentação do mesmo passam de acordo com esta nova perspectiva a ser dirigidos pelos turistas. O turista deixa de ocupar a parte final da cadeia produtiva para assumir um papel fundamental como co-criador do produto e dos destinos turísticos.

A produção de um destino turístico, como explicam Anjos, Anjos e Oliveira (2013), depende de uma programação integrada e interdisciplinar, considerando as necessidades e interesses sociais, de residentes, turistas e investidores, de modo a impulsionar a expansão da cidade caracterizando o turismo como fonte econômica do destino. O conteúdo é flexível e deve ser adaptado visando atender aos interesses da diversidade dos turistas bem como dos residentes, como componentes co-criadores do produto.

Para o funcionamento é necessário que haja interação entre todas as partes interessadas do sistema turístico, na formação de redes de cooperação, público-privadas, para a entrega de uma experiência de sucesso ao turista. Neste ponto as organizações de gestão do destino tem sua 
função ampliada para a integração dos esforços e gestão dos recursos.

A complexidade de gestão destacada por Crouch (2007 apud Vianna, Anjos \& Anjos, 2012) é muito maior do que a de uma simples firma individual, pois devido à variedade de empresas e de interesses envolvidos, faz-se necessário um amplo conhecimento do setor e uma integração de ações que permita serem evitados desperdícios em função da duplicidade de estruturas de controle e supervisão da implementação de políticas, diretrizes e estratégias de desenvolvimento do destino como um todo.

Com esta abordagem, pretende-se essencialmente chamar a atenção para uma nova forma de pensar o conceito de destino turístico, contribuindo para uma visão mais integrada da realidade que é este sistema dinâmico. Uma vez planejado e vivenciado, o destino turístico passa a fazer parte da memória dos turistas. As narrativas sobre o mesmo podem alimentar o imaginário de outros turistas que assim vão dando continuidade ao funcionamento do sistema.

\section{CONCLUSÃO}

A indústria do turismo cresce rapidamente, comprovada pelos números e estatísticas divulgadas pela UNWTO, e no centro dela está o destino turístico como ponto principal desta movimentação de turistas.

Encontramos na literatura do turismo varias abordagens sobre o turismo e que possuem perspectivas diferentes sobre o destino turístico. Tanto as abordagens da geografia, da economia, da sociologia, antropologia e psicologia criaram paradigmas e em seguida sofreram modificações e foram adaptadas às mudanças rápidas do ambiente e do comportamento do consumidor do turismo - o turista.

Nossa contribuição neste artigo foi de compilar algumas abordagens e mostrar que elas são complementares e dessa forma permitem outros estudos. Incorporamos nossa contribuição da visão integrada do destino turístico, descrevendo o destino como um sistema onde o turista vivenciará a sua experiência, sem fronteiras, cujo conteúdo é co-criado, onde deve haver cooperação e redes de empresas públicas e privadas, para a realização de uma experiência de excelência.

Esta visão integrada é sustentada e sofre a influência das transformações do ambiente de negócios, do mundo globalizado, das tecnologias de comunicação e da informação, que influenciam nos grupos sócio-territoriais onde estão os turistas e residentes. Bem como a mudança do comportamento do consumidor - mais informado, com mais acesso aos recursos de tecnologia de informação e mobile, exigindo ser parte integrante no processo de construção do produto, e, no caso do destino turístico, da experiência turística. Isso exige uma melhor compreensão do destino como um sistema integrado, flexível e adaptado às demandas.

Dessa forma, concluímos que, apesar de todas as abordagens serem úteis e complementares para se compreender de uma forma integrada a realidade que consubstancia o destino turístico, é a perspectiva dos turistas que deve prevalecer para a formatação do conceito. 


\section{REFERÊNCIAS}

Acerenza, M. A. (1987). Administración del Turismo: planificación y dirección. México: Trillas.

Andergassen, R., Candela, G., \& Figini, P. (2013). An economic model for tourism destinations: Product sophistication and price coordination. Tourism Management, 37, pp. 86-98.

Anjos, F. A. (2004). Processo de planejamento e gestão de territórios turísticos: um proposta sistêmica. Tese de Doutorado do curso de Engenharia de Produção. Florianópolis, UFSC.

Anjos, F.A.; Anjos, S.J.G. \& Oliveira, J.P. (2013). A Abordagem Sistêmica no Processo de Planejamento e Gestão de Territórios Urbanos Turísticos. Caxias do Sul. Revista Rosa dos Ventos, 5(3), pp. 390-407.

Becker, E.L.S. (2014). Geografia e Turismo: Uma Introdução ao Estudo de Suas Relações. Caxias do Sul. Revista Rosa dos Ventos, 6(I), pp. 52-65.

Beni, M. C. (2007). Análise estrutural do turismo. São Paulo: Editora Senac.

Buhalis, D. (2000). Marketing the competitive destination of the future. Tourism Management, 21, pp. 97116.

Cooper, C. (2001). Turismo: princípios e práticas. 2. ed. Porto Alegre (RS), Bookman.

Cracolicia, M.F., \& Nijkamp, P. (2008). The attractiveness and competitiveness of tourist destinations: A study of Southern Italian regions. Tourism Management, 30, pp. 336-344.

Crouch, G.I. (2007). Measuring tourism competitiveness: research, theory and WEF índex. In: Australian and New Zealand Marketing Academy (ANZMAC) Conference, Nova Zelândia, 3-5/dez, 2007. Disponível em: <http://conferences.anzmac.org/ANZMAC2007/papers/Crouch_1.pdf> Acessado em: 24 de abril de 2010.

Davidson, R., \& Maitland, R. (1997). Tourism Destinations. Hodder \& Stoughton Educational, London.

Framke, W. (2002). The Destination as a Concept: a Discussion of the business-related Perspective versus the Social - cultural Approach in Tourism Theory. Scandinavian Journal of Hospitality and Tourism, 2(2), pp. 92-108.

Graburn, N.H.H. \& Moore, R.S. (1994). Anthropological research on tourism. (In) Ritchie, J.R.B., \& Goeldner, C.R. Travel, tourism, and hospitality research: a handbook for managens and researchers. Canadá: John Wiley \& Sons, Inc.

Grant, R.M. (2005). Contemporary strategy analysis. Malden, MA: Blackwell. Publishing.

Handszuh, H. (2000). Models and Methodologies of Quality Assessment in Tourism. Worshop on Quality in Tourism: from Patterns to Indicators, Universidade do Algarve, Faro, Portugal.

Kastenholz, E., Carneiro, M.J., Marques, C.P., \& Lima, J. (2012). Understanding and managing the rural tourism experience-The case of a historical village in Portugal. Tourism Management Perspectives, 4 , pp.207-214. 
Laws, E. (1995). Tourist Destination Management. London, Routledge.

Leiper, N. (1979). Towards a definition of tourism, tourist, and the tourist industry. Annals of Tourism Research, pp.390-407.

Manente, M. (2008). Destinations management and economic background: defining and monitoring local tourist destinations. International Conference of Tourism. Malaga, pp.29-31.

Manente, M. \& Cerato, M. (1999). Destination Management: The Conceptual Framework. In: Manente M.; Cerato M. (Eds). Destination to Destination Marketing and Management: Designing and repositioning tourism products, Venezia, CISET/University of Venice Press, pp.15-28.

Manente, M., \& Furlan, M. C. (1998). Quality in the Macroeconomics System of Tourism. Revue de Tourisme, 2, pp.17-28.

Mendes, J.C. (2004). Gestão da qualidade nos destinos turísticos: o caso português. Tese doutoramento. Universidade do Algarve, Faculdade de Economia. Faro, Portugal.

Middleton, V.T.C. (1994). The marketing and Management of Tourism destinations: research directions for the next decade. 44 ème Congrés de l'Association International d'Experts Scientifiques du Tourisme, AIEST, Vienne (Austria), pp. 115-141.

Mitchell, L.S. (1994). Research on the geography of tourism. (In) Ritchie, J.R.B., \& Goeldner, C.R. Travel, tourism, and hospitality research: $a$ handbook for managens and researchers. Canadá: John Wiley \& Sons, Inc.

O'Neill, M.A., Williams, P., Maccarthy, M. \& Groves, R. (2000). Diving into Service Quality - the dive tour operator perspective, Managing Service Quality, 10(3), pp.131-140.

Pizam, A. (1991). The Management of Quality Tourism Destinations. 41 ème Congrés de l'Association International d'Experts Scientifiques du Tourisme, AIEST, Mahé (Seychelles), pp. 79-87.

Potron, F. (1988). Les marchands de 4 saisons. Espaces, 94, pp. 8-12.

Ritchie, J.R.B. \& Crouch, G.I. (1993). Competitiveness in International Tourism - a Framework for Understanding and Analysis. $43^{\text {rd }}$ Congress of the Association International d'Experts Scientifiques du Tourisme, San Carlos de Bariloche, Argentina, pp. 17-23.

Ross, G.F. (1998). The psychology of tourism (Second Edition). Hospitality Press Pty Ltd., Melbourne.

Salman, G., \& Asch, D. (2003). Strategy and capability. Malden, MA: Blackwell. Publishing.

Saraniemi, S. \& Kylanen, M. (2010 - Mar. 19). Problematizing the Concept of Tourism Destination: An Analysis of Different Theoretical Approaches. Journal of Travel Research. DOI: 10.1177/0047287510362775.

Silva, J.A., \& Silva, J.A.V. (1992). Turismo, Ambiente e Desenvolvimento Sustentável. Centro Interdisciplinar de Estudos Econômicos - CIDEC, Portugal.

Silva, J.A., Mendes, J.C. \& Guerreiro, M.M. (2001). A Qualidade dos Destinos Turísticos: dos Modelos aos Indicadores. Revista Portuguesa de Gestão, III (1), pp. 65-81. 
TANG, Liang (Rebecca). (2014). The application of social psychology theories and concepts in hospitality and tourism studies: A review and research agenda. International Journal of Hospitality Management, 36, pp.188-196.

UNWTO (2010) International Tourism on Track for a Rebound after an Exceptionally Challenging 2009 [online], Madrid, UNWTO - World Tourism Organization. Disponível em: http://www.unwto.org/media/news/. Acessado em: dez. 2013.

Vianna, S.L.G., Anjos, F.A. \& Anjos, S.J.G. (2012). Análise da Correspondência entre a Competitividade Percebida e a Competitividade Efetiva de uma Destinação Turística. Caxias do Sul. Revista Rosa dos Ventos, 4(IV), pp.486-505.

Artigo recebido em: 10/02/2014. Artigo aprovado em: 04/08/2014. 